\title{
RELATIVE COMPARISON OF STABILITY AND DEGRADATION OF METHYLCOBALAMIN TABLETS OF DIFFERENT BRANDS AT DIFFERENT STORAGE SETTINGS
}

\author{
ABDUL RAZIQ ${ }^{1}$, SYED UMER JAN ${ }^{1}$, RAHMAN GUL ${ }^{1,2^{*}}$, YOUSAF KHAN ${ }^{1}$, TAJALA AMAN ${ }^{3}$, PERVAIZ AKHTAR SHAH \\ ${ }^{1}$ Faculty of Pharmacy and Health Sciences, University of Balochistan, Quetta, Pakistan, ${ }^{2}$ Health Department Government of \\ Balochistan, ${ }^{3}$ Bolan Medical College Quetta, ${ }^{4}$ University College of Pharmacy, University of the Punjab, Lahore, Pakistan \\ Email: gul.dotani@yahoo.com
}

Received: 01 Mar 2021, Revised and Accepted: 05 Apr 2021

\section{ABSTRACT}

Objective: To assess relative comparison of stability and degradation of Methylcobalamin tablets of different brands at various storage circumstances.

Methods: The comparative in vitro study of Methycobal (innovator brand) with its other 5 different brands Cobalamin, Neuromet, Incobal, Qbal and Mecobal was organized for evaluation of physicochemical features of hardness, thickness, friability, weight variation, disintegration time and accelerated stability at 3 temperatures, $25{ }^{\circ} \mathrm{C}, 30{ }^{\circ} \mathrm{C} \pm 65 \%$ and $40{ }^{\circ} \mathrm{C} \pm 75 \%$ respectively for 3 mo. Later all brands were passed through HPLC for checking the extent of degradation of drug products.

Results: All tablet brands were within the weight variation specified limits except Mecobal with a relative standard deviation of $6.83 \%$. The weight variation values of Methycobal, Cobalamin, Neuromet, Incobal, Qbal and Mecobal were $0.29 \%, 0.11 \%, 0.09 \%, 0.13 \%, 0.09 \%$ and $0.14 \%$ after friability test respectively as per standard limits. The average thickness of Cobalamin, Incobal and Mecobal were not within specified limits. The average hardness of all trades was within limits except Cobalamin and Mecobal exceeding 6kp. The disintegration time of all companies was as per specifications.

Conclusion: Qbal was found economical and cost-effective. However, study facts unveiled no noteworthy variety in the Q. C assessments of Methylcobalamin brands.

Keywords: Stability, Degradation, Methylcobalamin, Storage

(C) 2021 The Authors. Published by Innovare Academic Sciences Pvt Ltd. This is an open access article under the CC BY license (https://creativecommons.org/licenses/by/4.0/) DOI: https://dx.doi.org/10.22159/ijap.2021v13i3.41263. Journal homepage: https://innovareacademics.in/journals/index.php/ijap

\section{INTRODUCTION}

Methylcobalamin, Mecobalamin, $\mathrm{MeCbl}$, and MeB12 all are declared terms used to identify vitamin B12 [1]. MeCbl is a therapeutically active segment of vitamin $B_{12}$, also applied in the management of Alzheimer's sickness, rheumatoid arthritis [2]. Vitamin B12 is necessary for cellular DNA production and therefore playing role in variety of functions of tissues in the body, development of myelin sheath, systemic circulation and gastro epithelial linings [3, 4]. Vitamin B12 is critical for actions of neurons, erythrocytes (RBCs) manufacturing, and is a cofactor for three foremost reactions; the transfer of methylmalonic acid to succinyl coenzyme A; the changing of homocysteine to methionine and the change of 5-methyltetrahydrofolate to tetra hydro folate [5, 6]. Maternal vitamin B12 shortage while pregnancy or during lactation can progress to neural tube faults, malfunction to flourish, hypotonic state, abnormalities in movement, and anemic situation. Females at higher hazard or with recognized deficit need to be supplemented with vitamin B12 throughout pregnancy or during breastfeeding or giving nourishment $[7,8]$.

There are various preparations applied to lessen the risk of scarcity of vitamin B12 like mucoadhesive buccal tablets, microencapsulated formulations, lozenges, liposomes, buccal films, nose sprays, intranasal drops, transdermal solubilized emulsions, mouth spray, gelatin parenteral dose shape, inhaler/pen, buccal mucoadhesion hydrogelic films and toothpastes etc $[9,10]$.

\section{MATERIALS AND METHODS}

\section{Study design}

Comparative in vitro quality control parameters amongst the commercially available tablet brands of Methylcobalamin innovator brand compared with it's five other different brands produced in Pakistan.

\section{Chemicals}

Methylcobalamin tablets of innovator brand Innov-B and other five Brands Cobalamin, Neuromet, Incobal, Qbal and Mecobal were chosen for the study project. 200 Tablets of each brand were purchased from local medicine market Quetta, Pakistan. Methylcobalamin was gifted by Martin Dow marker. All brands of Methylcobalamin contain $500 \mathrm{mcg}$.

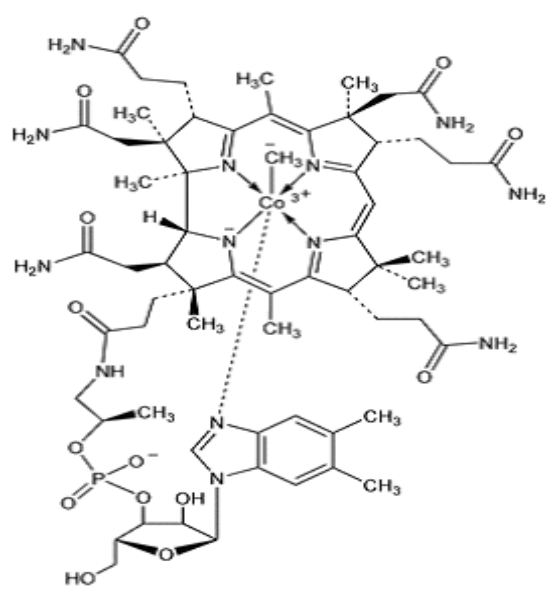

Fig. 1: Structure of methylcobalamin [11]

\section{Reagents for HPLC sampling}

Acetonitrile for Chromatographic process (Lichrosolv), Buffer solution $\mathrm{pH} 3.0+/-0.02\left(20{ }^{\circ} \mathrm{C}\right)$, (Citrated $\left.\mathrm{Hcl}\right)$, Mecobalamin reference sample, LiChrospher 100 RP-8 end-capped (10 micrometers), Disposable filter $0.45 \mathrm{um}$.

Instruments

Digital Electronic Balance, Vernier caliper, Disintegrator (Pharma tester), Hardness tester (Pharma tester), Roche Friabilator (Pharma 
tester), Stability chamber (Binder II-KBF720), HPLC apparatus (Shimadzu, LiChroCART 250-4 HPLC Cartridge) of analytical grade.

\section{Methodology}

The relative examination of Methylcobal with other five diverse companies including Cobalamin, Neuromet, Incobal, Qbal and Mecobal was systematized for valuation of physical and chemical attributes such as hardness, Thickness and Diameter, Friability, weight variation and accelerated steadiness at 3 temperatures, lab temperature, $30{ }^{\circ} \mathrm{C}$ and $40{ }^{\circ} \mathrm{C}$ by keeping relative humidity $\pm 65 \%$ and $\pm 75 \%$ correspondingly for 3 mo prior to stability testing as well as subsequently. Then innovator brand along with 5 other trades were passed through HPLC test for knowing the degradation of tablets of brands.

\section{Physical evaluation of methylcobalamin tablet brands \\ Weight variation test}

200 tablets of each brand were weighed in isolation with the abovementioned Digital analytical weighing balance and average weight and the percentage of variance was unveiled for every brand [12]. The equation for calculation of percentage weight variation is given below;

Percentage weight variation $=$ (average weight-individual weight)/individual weight x $100 \%$.

\section{Thickness test}

20 tablets of each brand were employed for thickness determination by Vernier caliper in $\mathrm{mm}$.

\section{Hardness test}

Tablet hardness is typically expressed as the load necessary to crush a tablet positioned on its perimeter and hardness is occasionally called tablet crushing force. The appropriateness of the tablet believed to mechanical stability at some point in wrapping and consignment would typically be forecasted on the criteria of hardness. The crushing potency was determined with a tablet hardness tester (Monsanto). Ten tablets were arbitrarily elected from each brand for this test [13].

\section{Friability test}

The trial was initiated by weighing 10 tablets overall that is measured as the initial weight, Wi. All the tablets being kept in the drum of friability tester and apparatus was revolved at $100 \mathrm{rpm}$ for $4 \mathrm{~min}$ ( $25 \mathrm{rpm}$ for $1 \mathrm{~min}$ ). Then tablets were deducted, and reweighed (just the intact ones). This is estimated as the ultimate weightage, Wf. Then the $\%$ age loss of weight of tablets was computed by utilizing the equation given under [13].

Percentage friability $=\{($ wi-wf $) /$ wi $)\} \times 100$

\section{Disintegration test}

Tablet disintegration was determined in the tablet disintegration Apparatus. 6 tablets from each brand were subjected to distilled water at $37{ }^{\circ} \mathrm{C}$. The disintegration time was taken to be the time no particle remained on the basket of the system [14].

\section{Stability studies}

All selected tablets of Methylcobalamin brands were targeted to constancy studies at 3 temperatures (lab temperature, $30{ }^{\circ} \mathrm{C}+65 \%$ and $40{ }^{\circ} \mathrm{C}+75 \%$ ) for three months in stability chamber as per International Conference on Harmonization (ICH) guidelines [15].

\section{Chemical assay}

\section{Mobile phase}

Acetonitrile LiChrosolve- $\mathrm{H}_{2} \mathrm{O}$-buffer solution $\mathrm{pH} 3,180 \mathrm{ml}+800$ $\mathrm{ml}+20 \mathrm{ml}$ ).

Because of the tremendous light sensitiveness of Methylcobalamin, the model solution and reference solution ought to be synthesized in a dark room. Cover the glass equipment used tightly in aluminium foil; darken the sample compartment of the autosampler with black paper.

\section{Sample solution}

Weigh 10 coated tablets in $50 \mathrm{ml}$ volumetric flask (equal to almost. 10 mg of Mecobalamin) with $50 \mathrm{ml}$ of $\mathrm{H} 20$ and shake mechanically for 60 min, build up the volume to the spot with $\mathrm{H} 2 \mathrm{O}$ and blend. Pass fraction of mixture via a disposable filter with the help of a disposable syringe.

\section{Standard solution}

Melt $50 \mathrm{mg}$ of Mecobalamin, correctly weigh, in water for making 100 $\mathrm{ml}$. Dilute $10 \mathrm{ml}$ of solution (alike to $5 \mathrm{milli}$ g of Mecobalamin) in $50 \mathrm{milli}$ liters V. flask, setup the volume up to the sign with distilled water.

\section{Chromatographic conditions}

The Apparatus of Liquid chromatograph with mechanical injection system, Detector (Ultraviolet Spectrophotometer) with Wave Length of $351 \mathrm{~nm}$ having Sample Volume of $50 \mathrm{ul}$ passed through a Column (LichroCART 250-4, LiChrospher $100 \mathrm{RP}-8$ ) end-capped (10 um) at a flow rate of $1.5 \mathrm{ml} /$ minute at a temperature of $40{ }^{\circ} \mathrm{C}$ along with running time of $20 \mathrm{~min}$ and retention time around about $4 \mathrm{~min}$.

\section{Method and assessment}

Inject the sample solution and standard solution each twofold. Find out the separate peak areas by integration.

\section{RESULTS AND DISCUSSION}

Label information of tablet brands

The Label known information about all brands are listed in table 1.

Table 1: Labeling information regarding samples

\begin{tabular}{lllll}
\hline B \# code & B \# No & Pr. (10) Tabs. & Mfg Date & Exp Date \\
\hline Methycobal & 129890 & 168 & Mar-2019 & Feb-2022 \\
Cobalamin & 9006 & 96.51 & Apr-2019 & Apr-2024 \\
Neuromet & Q596 & 133.90 & Feb-2020 & Feb-2023 \\
Incobal & 444 & 78.08 & Feb-2019 & Feb-2022 \\
Qbal & 19692 & 64.09 & May19 & Apr.22 \\
Mecobal & 003 & 82.69 & Feb-19 & Feb-22 \\
\hline
\end{tabular}

*Abbreviations: B \# No (Batch Number), Pr. (Price), Mfg (Manufacturing Date), Exp (Expiry Date), of the total batches (n=3).

Table 2: Physical manifestations of various brands

\begin{tabular}{lll}
\hline B-Code & Color & Coating \\
\hline Methycobal & White & Sugar Coated \\
Cobalamin & White & Sugar Coated \\
Neuromet & White & Sugar Coated \\
Incobal & White & Sugar Coated \\
Qbal & White & Sugar Coated \\
Mecobal & White & Sugar Coated \\
\hline
\end{tabular}

*Abbreviation: B-code (Batch code), of the total $n=3$ all batches show same color and coating. 
Gul et al.

Table 3: Weight uniformity of various brands

\begin{tabular}{lll}
\hline B-codes & Average weight (g) & Variation (RSD) NMT (6\%) \\
\hline Methycobal & $0.154 \pm 0.01$ & $3.09 \pm 0.01$ \\
Cobalamin & $0.208 \pm 0.02$ & $4.72 \pm 0.02$ \\
Neuromet & $0.157 \pm 0.01$ & $3.98 \pm 0.02$ \\
Incobal & $0.196 \pm 0.11$ & $5.791 \pm 0.01$ \\
Qbal & $0.101 \pm 0.01$ & $2.981 \pm 0.01$ \\
Mecobal & $0.018 \pm 0.11$ & $6.83 \pm 0.21$ \\
\hline
\end{tabular}

The values are expressed as mean $\pm \mathrm{RSD}=$ Relative Standard Deviation, $\mathrm{n}=3$. NMT= Not more than $6 \%$ \# Acceptance Criteria $<6 \%$.

\section{Weight uniformity of tablet samples}

All the selected tablet brands were within the weight variation specified limits except Mecobal with a relative standard deviation over $6.83 \%$ as affirmed in table 3 .

\section{Thickness of various tablet brands}

The average thickness of Cobalamin, Incobal, and Mecobal were not within limits of standard specifications as revealed in table 4.

Table 4: The average thickness of different batch brands

\begin{tabular}{ll}
\hline Batch codes & Average thickness $(\mathbf{m m})$ \\
\hline Methycobal & $3.753 \pm 0.02$ \\
Cobalamin & $4.374 \pm 0.11$ \\
Neuromet & $3.574 \pm 0.01$ \\
Incobal & $4.002 \pm 0.11$ \\
Qbal & $2.78 \pm 0.02$ \\
Mecobal & $4.295 \pm 0.02$ \\
\hline
\end{tabular}

All results values are mean of, $(n=3) \pm S D$, \# Acceptance criteria $<3.10$

\section{Hardness of tablet brands}

The average hardness of all brands was within the limits except Cobalamin (10.49 kp) and Mecobal (10.462 kp) above 6kp as described below in table 5 .

\section{Weight variation before and after friability tests}

The weight variation values $0.009(0.29 \%), \quad 0.005(0.11 \%)$, $0.03(0.09 \%), 0.003(0.13 \%), 0.002(0.09 \%)$ and $0.004(0.14 \%)$ of Innovator brand, Cobalamin, Neuromet, Incobal, Qbal and Mecobal after friability test respectively were within the standard limits of Specifications as given table 6 .

Table 5: The average hardness of various brands

\begin{tabular}{ll}
\hline Batch codes & Average hardness (kp) \\
\hline Methycobal & $5.78 \pm 0.02$ \\
Cobalamin & $10.49 \pm 0.01$ \\
Neuromet & $5.55 \pm 0.11$ \\
Incobal & $6.4 \pm 0.01$ \\
Qbal & $4.9 \pm 0.11$ \\
Mecobal & $10.462 \pm 0.21$ \\
\hline
\end{tabular}

*Abbreviation: kp (kilopond), All results values are mean of, $(n=3)$, \pm SD\# Acceptance criteria $=<8$

\section{Disintegration time of tablet brands}

The disintegration time of all brands was in the range 2-20 min as per the standard specifications as stated under in table 7.

Table 6: Weight values and variation before and after friability tests

\begin{tabular}{lll}
\hline B \# codes & Wt. before friability & Wt. after friability (g) Variation (g) (\%) \\
\hline Methycobal & $3.089 \pm 0.01$ & $3.080 \pm 0.020 .09(0.29 \%)$ \\
Cobalamin & $4.173 \pm 0.02$ & $4.168 \pm 0.010 .05(0.11 \%)$ \\
Neuromet & $3.176 \pm 0.01$ & $3.173 \pm 0.020 .03(0.09 \%)$ \\
Incobal & $2.244 \pm 0.01$ & $2.241 \pm 0.010 .03(0.13 \%)$ \\
Qbal & $2.014 \pm 0.02$ & $2.012 \pm 0.010 .02(0.09 \%)$ \\
Mecobal & $3.502 \pm 0.01$ & $3.497 \pm 0.020 .004(0.14 \%)$ \\
\hline
\end{tabular}

The values are expressed as weight before friability-weight after friability $\pm=$ Variance from the mean, of the total $n=3$

Table 7: Average disintegration times of different sample brands

\begin{tabular}{ll}
\hline Batch code & Disintegration time (Average) \\
\hline Methycobal & $10 \mathrm{~min}$ \\
Cobalamin & $20 \mathrm{~min}$ \\
Neuromet & $10-11 \mathrm{~min}$ \\
Incobal & $4 \mathrm{~min}$ \\
Qbal & $2 \mathrm{~min}$ \\
Mecobal & $5-6 \mathrm{~min}$ \\
\hline
\end{tabular}

All the values of total $(n=3)$ are mentioned as average disintegration time, \# Acceptance Criteria= $60 \mathrm{~min}$.

\section{Stability studies of tablet brands}

Stability of a biopharmaceutical product can be described as the capacitance of a specific preparation in a definite container/closure system to persist within its physical, chemical, microbiological, hazardous, defensive and informational specifications [16].
The objective of stability is to offer substantiation on how the superiority of a formulation differs with time under the effect of a diversity of environmental aspects

Like temperature, moisture, and light. Dilapidation is probably to arise under steamy environment of higher ambient temperature and humidity [17]. Therapeutic product stability is a multifarious 
collective procedure which needs substantial time, expenditure, utilization, and methodical skills to synthesize therapeutically efficient formulations, efficiency, excellence and safe nature [18].
The results of accelerated stability at 3 temperatures, lab temperature, $30{ }^{\circ} \mathrm{C} \pm 65 \%$ and $40{ }^{\circ} \mathrm{C} \pm 75 \%$ respectively for a duration of 3 mo were within the specified limits as revealed in table 8.

Table 8: Stability studies of chosen brands

\begin{tabular}{lll}
\hline Brands & Conditions & Stability Results \\
\hline Methycobal & $25^{\circ} \mathrm{C}$ & $99.13 \%$ \\
& $30{ }^{\circ} \mathrm{C} \pm 65 \%$ & $98.16 \%$ \\
Cobalamin & $40{ }^{\circ} \mathrm{C} \pm 75 \%$ & $98.02 \%$ \\
& $25{ }^{\circ} \mathrm{C}$ & $93.03 \%$ \\
Neuromet & $30{ }^{\circ} \mathrm{C} \pm 65 \%$ & $93.86 \%$ \\
& $40{ }^{\circ} \mathrm{C} \pm 75 \%$ & $93.39 \%$ \\
& $25{ }^{\circ} \mathrm{C}$ & $101.02 \%$ \\
Incobal & $30{ }^{\circ} \mathrm{C} \pm 65 \%$ & $101.72 \%$ \\
& $40{ }^{\circ} \mathrm{C} \pm 75 \%$ & $100.33 \%$ \\
Qbal & $25{ }^{\circ} \mathrm{C}$ & $111.03 \%$ \\
& $30{ }^{\circ} \mathrm{C} \pm 65 \%$ & $111.94 \%$ \\
& $40{ }^{\circ} \mathrm{C} \pm 75 \%$ & $109.71 \%$ \\
Mecobal & $25{ }^{\circ} \mathrm{C}$ & $96.51 \%$ \\
& $30{ }^{\circ} \mathrm{C} \pm 65 \%$ & $96.88 \%$ \\
\end{tabular}

Total (n=3) showed stability results at temp $25^{\circ} \mathrm{C} \cdot 30{ }^{\circ} \mathrm{C} \pm 65 \% \mathrm{RH}$ (Relative Humidity)and $40{ }^{\circ} \mathrm{C} \pm 75 \% \mathrm{RH}$ (Relative Humidity).

\section{HPLC sampling results and calculations}

The photosensitive material, mecobalamin, emerges at retention time of approximately $3.68 \mathrm{~min}$. Usual changing in the chromatography scheme can essentially cause changeable investigational surroundings. The endeavor of this measurement is to uphold a constant extrication performance. The chromatogram retention time is given in fig. 2 .

The results of HPLC of tablet brands are mentioned in table 9 and calculations are given underneath the table 9 .

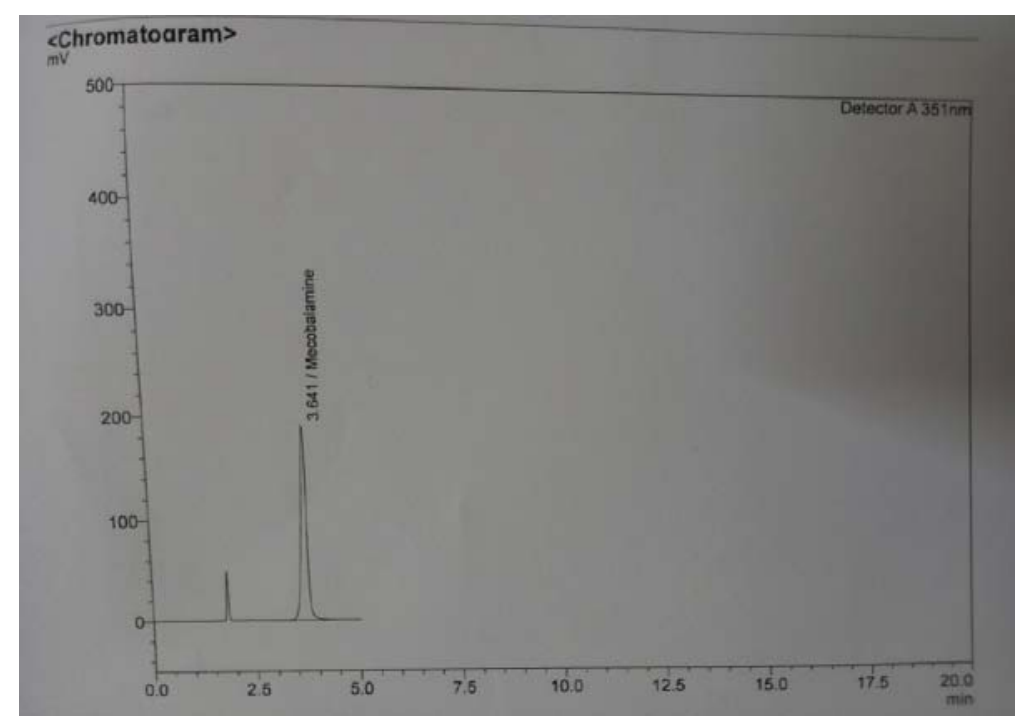

Fig. 2: HPLC results chromatogram of mecobalamin retention time 3.64

Table 9: HPLC facts about different brands

\begin{tabular}{llll}
\hline Product-B & B. No & Conditions & Mcg/Tablet Result \\
\hline Methycobal & 129890 & $30{ }^{\circ} \mathrm{C} \pm 65 \% 40{ }^{\circ} \mathrm{C} \pm 75 \%$ & 490.78490 .12 \\
Cobalamin & 9006 & $30{ }^{\circ} \mathrm{C} \pm 65 \% 40{ }^{\circ} \mathrm{C} \pm 75 \%$ & 469.29466 .96 \\
Neuromet & $\mathrm{Q} 596$ & $30{ }^{\circ} \mathrm{C} \pm 65 \% 40{ }^{\circ} \mathrm{C} \pm 75 \%$ & 508.58501 .67 \\
Incobal & 444 & $30{ }^{\circ} \mathrm{C} \pm 65 \% 40{ }^{\circ} \mathrm{C} \pm 75 \%$ & $53.16 \% 98.02 \%$ \\
Qbal & 19692 & $30{ }^{\circ} \mathrm{C} \pm 65 \% 40{ }^{\circ} \mathrm{C} \pm 75 \%$ & 42548.57 \\
Mecobal & 003 & $30{ }^{\circ} \mathrm{C} \pm 65 \% 40{ }^{\circ} \mathrm{C} \pm 75 \%$ & 483.34477 .23 \\
\hline
\end{tabular}

*Abbreviations: B. No (Batch number), Mcg (Microgram) at temp $25^{\circ} \mathrm{C} \cdot 30^{\circ} \mathrm{C} \pm 65 \%$ RH (Relative Humidity)and $40{ }^{\circ} \mathrm{C} \pm 75 \%$ RH (Relative Humidity) $=$. Results 


\section{Calculations}

A st $\mathrm{x}$ wtstd $\times 10 \times 50 \times$ P x Av. wt x $1000=$ mcg Mecobalamin $/$ tablet

As $\times 100 \times 50 \times$ wtsp $\times 100$

Where,

$\mathrm{A}_{\mathrm{s}}=$ Peak area of the sample solution

$\mathrm{A}_{\mathrm{st}}=$ Peak area of the standard solution $\mathrm{P}=$ Purity of the standard, in $\%$

Wtstd = Weight of standard taken, in mg Wtsp= Weight of the sample taken, in mg

Av. $\mathrm{Wt}=$ Average weight of the tablets

\section{CONCLUSION}

It was noticed that a larger discrepancy in worth in the identical generic brands of Methylcobalamin. Qbal with cost 64.09 Pakistani rupees/ten tablets was observed commercially efficient Nevertheless, as per the consequences of present readings disclosed no significant diversity in the qualitative analysis of Methylcobalamin brands. The superiority in stipulations of weight, thickness, disintegration, Friability and chemical evaluation (HPLC) were appraised, compared and found equivalent to one and other. Stability testing indicated every brand is comparable to other. Consequently, this is demonstrating that less rated medicines also offer excellent biopharmaceutical beneficial outcomes. Hence, it was summed up that the worth effectual drug ought be employed and may be recommended.

\section{ACKNOWLEDGEMENT}

The authors of this paper deeply acknowledged the Martin Dow Marker Lt, Quetta Pakistan and Faculty of Pharmacy and Health Sciences University of Balochistan, Quetta for providing us all the facilities during compilation of the research project.

\section{FUNDING}

Nil

\section{AUTHORS CONTRIBUTIONS}

We put forward a thesis topic entitled "Relative Comparison of Stability and Degradation of Methylcobalamin Tablets of Different Brands at Different Storage Settings" by Abdul Raziq, Dr. Syed Umer Jan, Dr. Rahman Gul, Yousaf Khan. Abdul Raziq, Dr. Rahman Gul carried out the industrial practical work, have interpreted the data and wrote the paper. All authors have examined the manuscript and are the guarantors.

\section{CONFLICT OF INTERESTS}

The Author of this article has no conflict of interest.

\section{REFERENCES}

1. McDowel LR, Williams SN, Hidiroglou, Njero N, Hill GM, Ochoa L, Wilkinson NS. Vitamins E supplementation for the ruminant Anim Feed Sci Technol 1996;60:296-73.

2. Zhang $\mathrm{M}, \mathrm{Han} \mathrm{W}, \mathrm{Hu} \mathrm{S}, \mathrm{Xu} \mathrm{H}$. Methylcobalamin; a potential vitamin of pain killer. Neural Plast 2013;6:651-424

3. Colledge NR, Walker BR, Ralston SH. Davidson's principles and practice of medicine. 21st edition. London Churchill Livingstone; 2010. p. 1020-2.

4. Sambulingam K, Sambulingam P. Essentials of medical physiology. New Delhi Jaypee Brothers Medical Publishers. $5^{\text {th }}$ edition; 2010. p. 73.

5. Hunt A, Harrington D, Robinson S. Vitamin B12 deficiency. Br Med J 2014;349:g52-26.

6. Stabler SP. Vitamin B12 deficiency. N Engl J Med 2013;368:160-49.

7. Langan RC, Zawistoski KJ. Update on vitamin B12 deficiency. Am Fam Physician 2011;83:1430-25.

8. Molloy AM, Kirke PN, Troendle JF, Burke H, Sutton M, Brody LC, et al. Maternal vitamin B12 status and risk of neural tube defects in a population with high neural tube defect prevalence and no folic acid fortification. Pediatrics 2009;123:923-17.

9. Monto RW, Rebuck JW, Brennan MJ. Inhalation and nasal instillation of crystalline b12 therapy in pernicious anemia. Henry Ford Hosp Med J 1953;1:20-15.

10. Mohamad SA, Abdelkader H, Elrehany M, Mansour HF. Vitamin B12 buccoadhesive tablets, auspicious non-invasive substitute for intramuscular injection formulation, in vitro and in vivo appraisal. Drug Dev Ind Pharm 2019;45:244-51.

11. Chamle AH, Shane NLJ, Pai A, Muddukrishna BS Photodegradation of methylcobalamin and its determination in a commercial formulation. Indian J Pharm Sci 2019;81:62-57.

12. Rahman ZU, Khan I, Baig A, Quraishi AR, Zahir. Post-market in vitro comparative evaluation of quality control parameters of paracetamol compressed tablets manufactured in local industrial zones of kpk Pakistan. Pharma Innovation J 2013;2:15-1.

13. Karmakar P, Kibria MG. In vitro comparative evaluation of quality control parameters between paracetamol and paracetamol/caffeine tablets available in Bangladesh. Int J Curr Pharm Res 2012;1:109-3.

14. Chandrasekaran AR, Han CY, Yang AC, Cheang LW, Ping LS Post-market in vitro equivalency evaluation of paracetamol tablets in Kedah, Malaysia. IJPSN 2011;4:1407-3.

15. HT Guideline. Stability testing of new drug substances and products. QIA (R2), Curr Step 2013;4:24-1.

16. Bajaj S, Singla D, Sakhuja N. Stability testing of pharmaceutical products. J Appl Pharm Sci 2012;2:129-38.

17. Mahor A, Alok S, Gupta Y, Jain S. Body distribution and stability studies on mitoxantrone loaded solid lipid nanoparticles conjugated with concanavalin a. Int J Pharm Pharm Sci 2010;2:42-39.

18. Zothanpuii F, Rajesh R, Selvakumar K. A review 0n stability testing guidelines of pharmaceutical products. Asian J Pharm Clin Res 2020;13:9-3. 